\title{
The role of the NHS Health Advisory Service
}

\author{
Richard Williams and Ray Travers
}

\begin{abstract}
In this article, the Director of the NHS Health Advisory Service describes the task which he was given upon appointment and the new roles of the HAS. A senior reglistrar in forensic poychiatry illuminates one of lis new roles by describing his aftachment.
\end{abstract}

In 1969, the Hospital Advisory Service was established to aid improvement of the management, organisation and standards of delivery of patient care, mainly, for elderly and mentally ill people in hospitals in England and Wales and to advise the Secretaries of State about conditions in them. Its establishment followed from the enquiry into conditions at Ely Hospital in Cardiff.

In 1976, when it became the NHS Health Advisory Service (HAS), community services for mentally ill and elderly people were added to the remit. Later, in 1986, the NHS Drug Advisory Service was created to support the implementation of policy on services for people who misuse drugs. This organisation has functioned in conjunction with the HAS as the appointments of Director have been held by the same person and the support services have been found by the same organisation.

\section{The Director speaks}

\section{The Ministerial review of the HAS}

After a Ministerial review completed in 1991, it was announced that the HAS would keep its remit in relation to health services for elderly people and people with mental illness but that its roles would be adjusted and extended to take account of the NHS reforms. The task I was given is best described by the expectations for the HAS which I met upon appointment. These lay in two broad areas.

(a) To discharge an inspectorial and advisory role in response to commissions from Ministers. These commissions may relate to specific themes but could include more general examinations of local services.

(b) To provide advisory or consultancy services in response to regional health authorities as the bodies responsible for oversight of district health authorities - the purchasers of health services - and to ensure that purchasing health authorities secure health care of quality and volume appropriate to the needs of the populations they serve.

\section{Strategic developments}

During the first six months, I was concerned with determining how these 'missions' might be achieved. A strategic review was conducted by the Directorate and from this five broad types of HAS activity were developed. These are as follows:
(a) thematic reviews
(b) Ministerial reviews
(c) specialist advisory services
(d) the local review and consultancy service
(e) Directorate and headquarters services.

Early on, work undertaken in visits to services, drew my attention to a number of challenges facing them and this seeded my decision to carry out a benchmarking exercise by holding a series of consensus meetings on services for each of the main client groups of the HAS. The client groups are:

(a) people of all ages with a mental illness

(b) elderly people

(c) people who misuse substances.

Each of the meetings did produce a consensus on the vital issues which were seen as facing both the purchasers and providers of services. Those in attendance included the staff of services from regional, district and primary care levels. Care was taken to include members of each of the key professional disciplines who work in these services as well as managers. Additionally, a seminar on substance misuse services and a working group to consider the role of clinicians, of all disciplines, in service management were held.

As a result, refinement of my strategy for the HAS, aimed at achieving the Ministers' requirements, occurred and I became bathed in helpful opinion about those professional, managerial and resource issues which face services now. The results, covering both the strategic direction of 


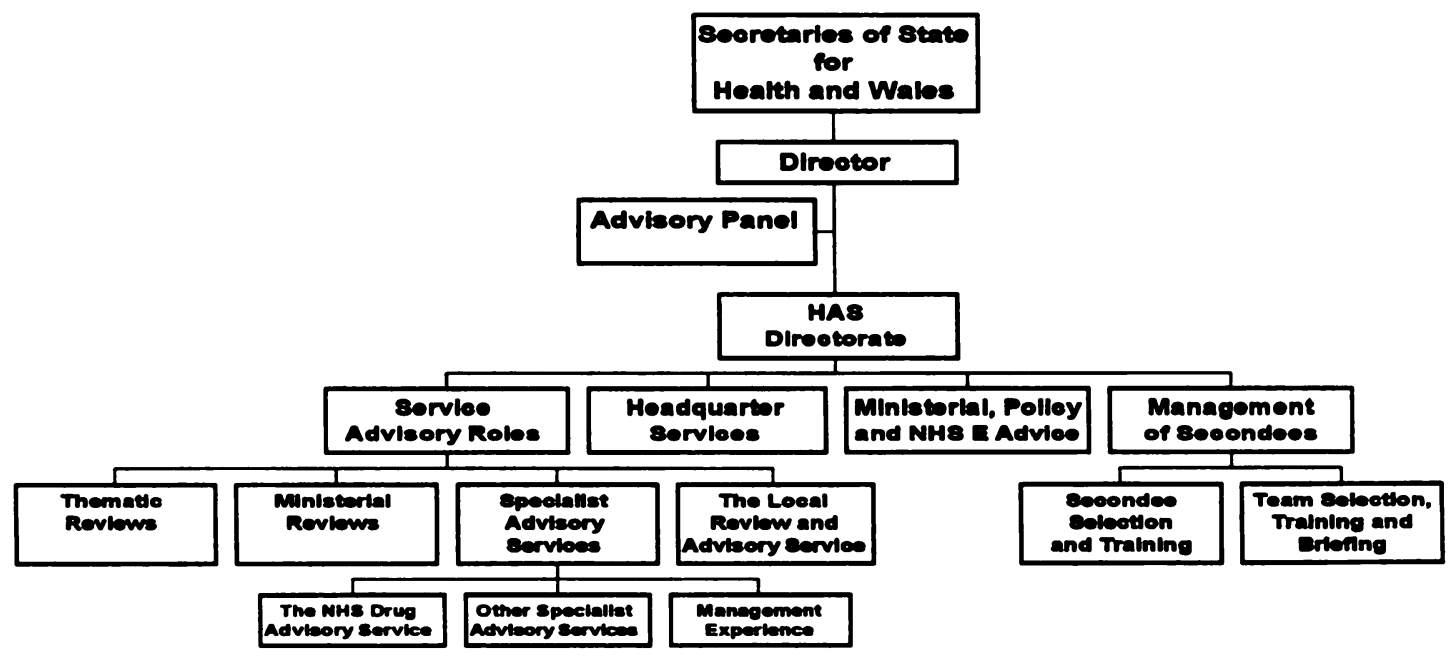

Fig. 1. The NHS Health Advisory Service

the HAS and summaries of the consenses reached, were published in my Annual Report for 1992-93 (HAS, 1993).

Since then, each of the new areas of activity of the HAS have been developed in detail, tested and refined. The organisational diagram, Fig. 1, summarises the current work of the HAS.

\section{The activities of the HAS}

Thematic reviews. These are carried out on a national basis with the aim of promulgating good practice and advising purchasers on strategy, health investment planning, needs assessment, contract specification, service monitoring and quality assurance related to the client groups covered by the HAS. Visits to local services are conducted in order to provide a picture of local provider services and the quality of purchaser functioning, to illuminate good practice and to identify practical matters which should influence the advice required by purchasers and providers.

Presently, the HAS is conducting some seven thematic reviews which concern the commissioning, role and management of mental health services for children and adolescents, the special aspects of purchasing and providing mental health services for homeless mentally ill people, the multidisciplinary assessment of elderly people, purchasing and providing substance misuse services for young people and a review of mental health contract and commissioning documentation.

In addition, the HAS is collaborating with the Clinical Standards Advisory Group in its review of standards of services commissioned and provided for people with schizophrenia.
The report of a thematic review into suicide prevention was published in July 1994 (HAS, 1994).

Ministerial reviews. The HAS continues to be commissioned by Ministers to undertake reviews of services which are either causing concern or upon which guidance is required. One such report of work conducted jointly with the Mental Health Act Commission and the Social Services Inspectorate on adolescent forensic psychiatry services was published in June 1994 (HAS/ MHAC/SSI, 1994).

The specialist advisory services. During the Ministerial review of the HAS, it was determined that the work of the NHS Drug Advisory Service would continue substantially unchanged, although adjustments to its approach are being made to enable it to play a full role within the reformed health service.

The local review and consultancy service. This service provides a continuing programme of reviews on a local basis negotiated between the HAS and, until recently, the intermediate tier of management of the NHS. Specific advice is offered to purchasers and providers on developing the quality of their services and remedying problems.

Directorate and headquarters services. One of the major responsibilities of the HAS is that of advising Ministers and the NHS Executive. This advice is generated by extracting general themes from the observations made during HAS service visits. 
A consequence of the widened role of the HAS was a review of the internal organisational structure and management of the HAS headquarters, conducted to enable the changed range of activities to be supported.

\section{Issues arising from the work of the HAS}

During the course of my first year in post, a number of issues of concern and opinion emerged from visits to services and my contact with the many staff at all levels who purchase and provide them. A commentary on each of them appears in my Annual Report for 1992-93. I comment on a selection here.

Purchaser expertise. Care in the community has made it imperative that purchasers of services for mentally ill and elderly people should develop expertise in designing strategies for services which reflect the clinical realities. In many instances, it has appeared to me that this expertise is under-developed, particularly with regard to those services for the vulnerable groups which are of concern to the HAS. The HAS has considered how it might achieve its aims within the reformed health service and, as earlier paragraphs signify, my own view was that the HAS should be involved not only with the standards of service provision but, increasingly, in supporting purchasers with developing expertise which carries credibility with service users and clinicians. During 1992-93, Ministers extended the remit of the HAS by giving it explicit responsibilities for monitoring the quality of health care and the performance of purchasers. So the HAS now endeavours to review both the commissioning and provision of services when it undertakes all aspects of its activities, including its local reviews.

Viston and leadership in services for vulnerable people. During my first year in post, it became clear to me that not only are high standards of practice and management vital to the achievement of high quality services for the vulnerable groups with which we are concerned, but of critical importance are the leadership qualities of the staff within those services. My discussions with other professional and advisory bodies revealed that this was a broadly held view. Consequently, I was asked to add an additional thematic review to my work programme to study both the challenges to leadership and their resolution in services. This is being conducted through the medium of a top management programme. It is hoped that the review will make recommendations as to the support and training of key persons. The work is being conducted jointly by the HAS, the Institute of Health
Services Management, the Royal College of Psychiatrists and the Royal College of Nursing.

Other matters. I have given some emphasis to two matters but others on which I commented included: the composition of NHS trusts, purchaser-provider communications and personnel policies. A number of other contemporary issues which were identified as facing purchasers and providers in achieving high quality services included:

(a) assessment procedures

(b) a focus on actual and potential disability

(c) the design of comprehensive integrated services

(d) the importance of liaison and consultation services

(e) effective information systems, audit and research.

In addition, my review of the work of the HAS revealed to me just how powerful an experience a visit to a service can be, not only for recipients of the review but also for those seconded people who undertake it. In essence, I would hope that a review of a service undertaken by, say, five individuals would affect six services - the service reviewed and, through the impact on the reviewers, the services from which they come. It seemed clear to me that there was the possibility of other gains to be reaped from this experience which could have a longer term impact through seeding better understanding of management on one side, and the clinical realities on another, of both clinicians and managers through the attachment of trainees to visiting teams. Consequently, I have explored these possibilities through the attachment of a management trainee and, more recently, a senior registrar. Rather than my endeavouring to describe this venture I anticipate that readers would prefer to hear from a trainee direct. So over to you Ray.

\section{A trainee speaks}

Following an announcement in the Psychiatric Bulletin in June 1993, I was privileged to be selected as the first senior registrar in psychiatry to participate in an HAS visit. When I spoke initially to Richard Williams on the phone, I was unsure about the nature and scope of the HAS and how an attachment might improve my managerial acumen. I was very eloquently persuaded that my involvement would enhance my understanding of both the nature of management in the reformed NHS and the potential contribution of organisational analysis in developing an appreciation of the dynamics of organisations. Furthermore, the opportunity for experiential learning would allow me to acquire 
certain skills in strategic and operational management practice. Immediately seduced, I accepted my invitation with alacrity. Looking back now, I can confirm that my high expectations were not disappointed. It was a 'hard graft' at the time but I found the experience both stimulating and enjoyable. I share my impressions with you, hoping that this will encourage more senior registrars to compete for an attachment in $\mathrm{Dr}$ Williams' initiative.

The length of HAS visits vary depending on the remit of each and the visit I participated in involved two weeks of fieldwork followed by a further week at the HAS headquarters in Sutton, Surrey. On this occasion the team consisted of two consultant psychiatrists, and senior managers from nursing, occupational therapy, social services and the NHS. In the month prior to the fieldwork, each team member received a two-foot high file of documents covering every aspect of the mental health services in the area to be visited. The information made available to us was very comprehensive in its scope, ranging from glossy brochures to statements of strategic intention, an environmental health officer's report on the hospital kitchens and Community Health Council correspondence. The briefing meeting, two weeks later, gave a fascinating opportunity to observe how the individuals came together as a team as they focused on the key issues and priorities for the visit. The cohesiveness of the group was facilitated by its determination to rid itself of non-essential documentation, especially after the team leader announced that each member had to take his/ her pile home on the train! By the end of the briefing session, the team had a unique perspective on the mental health service to be visited and, in some ways, we seemed to know more about it than the purchasers and providers did themselves. The briefing meeting proved vital to the success of the visit as it enabled a clear sense of the various agendas to be formed.

During a HAS visit, team members meet a very large number of individuals at all levels in health and local authority and voluntary services. On this occasion, we had face-to-face contact with a very wide spectrum of key people ranging from chairmen to chief executives through to self-help groups and users. We canvassed at every level and from as many agencies as was possible. The dynamics of these meetings were fascinating to observe. Our initial meetings with both the purchasing and providing management teams were of particular interest. Both teams maintained clearly demarcated boundaries. Certain key personnel seemed to avoid direct eye contact with each other and the positioning of individuals left one in no doubt about where the real power and influence lay. The process of separating rhetoric from realism was very enlightening.
Noting the constant state of flux at the clinicalmanagerial interface and pinpointing the various catalysts and associated factors that were influencing this dynamic equilibrium were invigorating exercises. In some sense it reminded me of how I had felt observing a family from behind a screen when I was a registrar. By being once removed, the HAS team has the space to reflect on what is happening and feed this back, appropriately, to the service being visited. Furthermore, the dynamics of the visiting team itself appeared to evolve as the visit progressed. Initially, we had to resist temptations to assume an adversarial role while, at the same time, trying to establish the facts and the nature of the relationships between the major players. Later on, as the team grasped the overall picture, we adopted a more supportive role. In some ways the team abandoned its neutrality as it began to share its insights with the services it was visiting long before it made a formal feedback to them.

An important feature of an HAS visit is the series of feedback sessions in the closing days in the field. Good feedback is a very demanding and difficult function. Like the blending of a fine whisky, there is a little 'magic' to the process of repeated distillation of the facts and figures gathered. The team has to work under intense pressure to prepare its presentation so that it conveys its messages in a constructive manner. The final feedback presentation is a public occasion when the team's verbal fluency and professional tact must be skilfully woven. The visit over, the team then retires to the HAS London headquarters where the report is drafted with each member responsible for a particular section. Vital ingredients at this stage include endless patience, diligent application and acceptance of compromise. The final draft must reflect a consensus view ... no mean task when I consider the debate that occurred at times during the writing of my particular report.

The reformed NHS poses many challenges to both managers and clinical staff as they attempt to deliver effective care in an equitable manner to those who need it most. In my opinion, the analogy of the young child struggling to keep her balance as she makes her first few steps is an apt description of how many purchaser and providers view themselves at the moment. However, there are certain recurring themes that appear universal to all, despite inevitable differences between services. Many are finding it difficult to develop coherent district wide strategies that are based upon the assessment of local needs. Intentions are difficult to translate into strategles. Policies are not necessarily being implemented effectively at an operational level. There may be an excessive degree of distrust between 
purchaser and provider units. Managers are struggling to 'manage change' as their organisations are restructured. Communication is problematic and many clinical disciplines feel isolated and unsupported.

The visit helped bring some of these themes sharply into focus for me. My appreciation of the importance of strategic planning has been enhanced. I am much more aware of the potentially powerful role of joint purchasing initiatives involving health authorities, local authorities and GP fund-holders. I can see now how interagency relationships and personality factors can influence both policy and operational issues in any given district. I discovered some very useful tips on how communication can either be facilitated or inhibited at various levels in an organisation and about the impact these matters have on how well the service is integrated and staff morale is maintained. I can more readily appreciate how the structure of an organisation can lead to a genuine orientation toward the patients or, less satisfactorily, towards the professional staff. Working alongside senior managers has exposed me to a rich variety of managerial concepts and practices. Although the subject of 'managing change' has a vast literature, a simple lesson I learnt, which I feel is a particular significance for the NHS, is that managers should be visible to their staff. They should lead from the front and not from the executive offices. A core feature of the NHS reforms is the push to more devolved budgets. Knowing how far to devolve them and to whom are not easy matters to handle, and I do not envy the managers their tasks. As one senior manager wryly commented, "When times are good it goes down, when bad it comes back". Finding the correct balance between managerial and functional responsibility (ie, the clinical directorate role) is like prescribing above the BNF limits - it requires skill and courage!

A period of attachment to the HAS for a senior registrar has both its virtues and its vices. It offers managerial experience at the 'coal-face' helping real people in real services with real problems. You can share their dreams and their pain and, if you are lucky, make a few helpful interventions. And the down side? Well, you might be seduced into thinking that, with the right calibre of managerial expertise, you could be a more effective consultant for your patients.

\section{Concluding remarks}

It will be clear to readers that the HAS has undergone a period of rapid and significant change since the Ministerial review was completed in 1991.

The Director has endeavoured to build on its past successes of role and methodology, based on the wisdom of clinical peers, and to couple the hard-worn experience of the HAS with the opportunities given by the reformation of the health service. The aim remains the same - that of contributing to maintaining and raising standards.

It may be that a number of the changes consequent on the Ministerial review are thought to be controversial by some. Concerns have been expressed about the move away from a cyclical programme of reviews, but the Director hopes that the way in which he has been enabled to take forward the changes required of the HAS will go some way towards reassuring those who have expressed concern. A large volume of activity is still based on the choice of local services for review being made either centrally or by those with monitoring responsibilities from outside them. The intention now is to sustain and build on the key position of the HAS such that it can continue to exercise an influence on, not only the performance of local services but also on the implementation of policy in ways which are clinically realistic. The Director hopes that, by contributing to the development of leadership, management, the support of key members of staff, and commissioning skills, the HAS will have a long-term impact on service quality.

\section{References}

NHS HeAlth AdVISORY SERvice, (1993) A Unique Window on Change - The Annual Report of the Director for 1992-93. London: HMSO.

- (1994) Suictde Prevention-The Challenge Confronted. London: HMSO.

-, Mental Health act Commission. Soclal Services InspecTORATE, (1994) A Review of the Adolescent Forensic Psychitry Servites based on the Gardener Unit. Prestwich Hospital, Salford, Manchester.

Richard Williams, Director, NHS Health Advisory Service, Sutherland House, 29-37 Brighton Road, Sutton, Surrey SM2 5AN; and Ray Travers, Senior Registrar in Forensic Psychiatry, North West Regional Health Authority, Hamilton House, Pall Mall, Liverpool 